\title{
FEMINILIDADE E MODERNIDADE EM FREUD: UMA LEITURA CRÍTICA
}

\author{
Marcelo Ricardo Nolli ${ }^{1}$
}

\section{RESUMO}

Trata-se neste artigo de discutir a relação entre modernidade e feminilidade, a partir de Freud. O objetivo reside em delimitar a psicanálise como uma teoria e uma prática clínica que surgem propriamente devido às estruturas sociais da modernidade, tendo como uma de suas pedras fundantes a sexualidade feminina. Lança-se mão, para isso, de W. Benjamin, no campo da Teoria Crítica, e de Flaubert, Klimt e Baudelaire, no campo da produção estética. De cunho interpretativo-hermenêutico, busca-se estabelecer uma leitura crítica entre os textos de Freud e sua época, de modo a tentar compreender como sua teoria é produto de seu tempo, ao passo que também está à frente dele, produzindo novas formas de compreensão sobre a subjetividade moderna.

PalaVRas-ChaVe: Psicanálise. Feminilidade. Modernidade. Gênero.

\footnotetext{
1 Graduado em psicologia pela Universidade de Passo Fundo (2018), Mestrando do Programa de PósGraduação em Educação da Universidade de Passo Fundo (Bolsista CAPES). E-mail: 145493@upf.br Telefone 54 99105-8205. ORCID https://orcid.org/0000-0001-8760-7822
} 


\section{INTRODUÇÃO}

Nos diários não publicados de Marie Bonaparte, há um comentário bastante alusivo sobre uma conversa entre ela e Freud. Ela teria dito que "O homem tem medo da mulher", no que Freud teria respondido: "Ele tem razão!" (GOLEMAN, 1985; GAY, 1989 , p. 473). Ora, um comentário como esse talvez nos mostre mais do que uma simples brincadeira; talvez nos indique como há um certo sintoma que precisou encontrar suas vias na produção estética, ou, mesmo, na obra de Freud, para ganhar vazão. Um sintoma que pode ser reconhecido no estranho que está à espreita no velho chavão do "continente negro da psicanálise" e que talvez nos indique mais sobre o tempo histórico de Freud - e mesmo sobre o criador da psicanálise - do que sobre alguma condição natural no que se refira aos caminhos da feminilidade.

Deste modo, cumpre delimitar o escopo do artigo: de início, procura-se apresentar a construção cultural sobre o feminino, vinculada aos discursos artísticos. É lançado um olhar sobre o contexto cultural europeu que tem seu auge na belle époque e surge em meados do século XIX, utilizando-se de leituras sobre a modernidade e de obras que retratam a mulher e que vieram influenciar a percepção do suposto enigma feminino - enigma esse ao qual, lembrando com Charcot, acreditava-se ter em sua base "toujours la chose génitale!". ${ }^{2}$ O que se busca evidenciar é que as leituras realizadas pela arte e pelo campo científico relegam à mulher uma posição de sujeito que deve ser compreendida como efeito de um campo discursivo; são as vias de construção deste campo e seus atributos de linguagem que denotam a relação que se estabelece entre a diferença sexual e o lugar que a mulher ocupa na estrutura social da época.

Por isso, indaga-se: qual é a relação entre a modernidade e a psicanálise no que se refere à representação da mulher em Freud? Para responder, evocamos autores que discutem o tema da modernidade e seu contexto, e também antecessores de Freud que moldaram no imaginário social elementos que serviram de base para a

\footnotetext{
2 "Sempre a coisa genital": razão da qual as histéricas sofreriam e produziriam seus sintomas. É uma fala de Charcot relembrada na Contribuição à história do movimento psicanalítico (1914, p. 13). Interessante que nessa pequena lembrança retratada, Freud teria pensado em responder "E se sabe, por que não lhe diz isso?". Esse era o ponto de convergência, que apesar de ter sido esquecido por algum tempo e relembrado anos depois na escrita do texto, antecede a criação da terapia psicanalítica e da compreensão de que na base da etiologia neurótica se encontra sempre, com uma pequena correção no que seu mestre havia dito, la chose sexuèlle.
} 
construção de sua teoria e que representam, em partes, o espírito de sua época. Tal perspectiva que centre o olhar sobre o "estilo vitoriano" da época não se quer monolítica, até porque, como bem observa Peter Gay (p. 461), esse estilo é repleto de descontinuidades, contradições e ambiguidades, incapazes de serem expostas de forma unívoca. Mais vale o empenho de lançarmos o olhar sobre os particulares que, apesar de não esgotarem o tema, podem nos dar indicativos de sentido sobre o todo global de tal época.

\section{Fin DE SiÈCle: RePRESEntaÇões do Feminino na Modernidade}

Como aponta Neri (2005), a modernidade desponta com uma crise de identidade própria do sujeito moderno; ela apresenta uma crise do sujeito clássico da razão associada a uma crise da identidade sexual. Com a Revolução Francesa (1789) há o prenúncio da morte do rei, a morte do pai e a morte de Deus. Neri observa que "o advento da democracia é incompatível com a autoridade paterna vigente. Liberdade, igualdade e fraternidade substituem a submissão, hierarquia e paternidade" (NERI, 2005, p. 61). Decorre então que, com a perda de uma unidade transcendental metafísica que pudesse explicar as razões de todas as diferenças e assimetrias na organização social, a ciência ganha corpo como sistema que se torna hegemônico na busca de respostas para os grandes problemas da humanidade - e falha em larga medida nesse processo. Diante desse contexto, a modernidade vienense "vai expressar de forma contundente em suas obras o inquietante questionamento da identidade sexual do homem moderno" (NERI, 2005, p. 67), ao passo que também se associa "com a ruptura política inaugurada pela Revolução Francesa, que marca a modernidade" (NERI, 2005, p. 71). A humanidade será, então, "entendida em sua história e rompem-se estruturas seculares: [...] conduzindo a uma interrogação sobre a diferença dos sexos num século onde vai se debater enfim a igualdade de todos os seres" (NERI, 2005, p. 71).

Ora, frente a esse contexto, no campo da produção estética, o século XIX mostrará um rompimento com o romantismo - o que implicará em uma descrença com os ideais metafísicos ainda fortemente marcados pelas estruturas tradicionais anteriores à modernidade. Nomes como Charles Baudelaire, Arthur Rimbaud, Stéphane Mallarmé, George Sand, Gustave Flaubert, entre outros, buscaram dar sentido à época em que viveram enquanto moldaram a percepção dela. Tal incursão 
na produção estética da modernidade pode ter como base a tentativa de captar a experiência do século XIX empreendida por Walter Benjamin, filósofo alemão e expoente da Escola de Frankfurt. Para Benjamin (2003a), uma figura alegórica e exemplar da modernidade pode ser localizada no flâneur. ${ }^{3}$ Tal figura, diferente do caminhante que decididamente vai de um lugar ao outro pelas ruas parisiense, se deixa afetar por elas, absorvendo a complexidade e a vivacidade da civilização que começa a surgir no século XIX. A indeterminação paira sobre os sujeitos, e o desconhecimento do futuro, das mudanças sociais, industriais e culturais são constantes que afetam diretamente o modo de vida e de sofrimento desses sujeitos.

Uma das grandes obras no que diz respeito à poesia moderna, As flores do mal, de 1857, causou um estardalhaço de proporções incontornáveis na vida social europeia do século XIX. Baudelaire foi processado pelo regime do Segundo Império por utilizar-se de imagens chocantes para o público leitor, notadamente a evocação de imagens de desejo homossexual entre mulheres. Como Benjamin (2003a, p. 56, tradução nossa) expõe: "A lésbica é a heroína da modernidade. Nela, um dos ideais eróticos de Baudelaire - a mulher que simboliza firmeza e virilidade - se combina com um ideal histórico, aquele da grandeza do mundo antigo". Aqui a mulher apresenta traços masculinos, na inversão que coloca em jogo o desejo feminino como aquele que possui mais propensão à não-rigidez da heteronormatividade. Contudo, o que Benjamin observa é que essa figura da mulher que Baudelaire apresenta em seus poemas surge como uma heroína aos moldes dos heróis da Grécia antiga. Nesse ponto, é importante atentar que o autor procura estabelecer relações alegóricas com as imagens que essas figuras evocam; isto é, pensar através de imagens é estabelecer uma relação dialética entre o presente e o passado, de tal modo que as ruínas do passado sejam escombros que ainda no presente estão vivos e determinam a nossa relação com essas imagens. Nesse sentido, Baudelaire em sua crítica da obra de Constantin Guys, observa que "A modernidade é o transitório, o efêmero, o contingente, é a metade da arte, sendo a outra metade o eterno e o imutável"

\footnotetext{
${ }^{3} \mathrm{~A}$ importância do flâneur na história da época se deve ao fato de que ele representa o descentramento do sujeito frente aos avanços da civilização e à massificação da cidade urbana, que passa a receber uma alta quantidade de habitantes. Esse descentramento é o que, segundo Benjamin (2003a), irá constituir o homem moderno como desamparado e perdido frente à dissolução dos vínculos estáveis com a realidade, tentando dar sentido e encontrar respostas - mesmo que através da arte - aos problemas da época. A ida dessa figura característica ao centro de Paris, às "passagens", para observar o mundo social que se abria à sua volta, desengajado da rapidez que os pedestres passavam em busca de commodities não só no nível do consumo, mas das próprias relações sociais, simboliza bem a situação de ruptura com formatos anteriores de vida social.
} 
(BAUDELAIRE, 2006, p. 859). Isso se expressa na diferença em relação ao contexto social tradicional anterior; entre a estabilidade de estruturas rígidas e a rapidez das mudanças que começam a ocorrer com o advento modernidade.

Como Adorno e Horkheimer (1985) expressam na obra "Dialética do esclarecimento", publicada em 1947, é possível de localizar na era moderna a presença da figura do herói da mitologia grega como representante do modelo de subjetivação próprio à modernidade. O culto do indivíduo - capaz de enfrentar o destino por si só através de seus méritos e de sua determinação para superar os problemas que a realidade apresenta, como o herói da Odisseia - determina a subjetividade moderna. É relevante apontar que o retorno aos heróis e à mitologia da Grécia antiga foi um movimento amplo na segunda metade do século, realizado não apenas por poetas, mas também pelos pintores e escritores, tendo em vista que "os mitos e símbolos trazidos da Grécia primitiva revelaram-se um instrumento poderoso de desnudamento da vida instintiva, que fora sublimada ou reprimida na tradição clássica" (SCHORSKE, 1988, p. 212). Nesse sentido, há uma relação muito íntima entre o movimento simbolista e a cultura da Antiguidade, por exemplo.

Como é observado por Benjamin (2003a), o empenho de Baudelaire se dá em dotar de características andróginas, ou até mesmo masculinas, a figura da mulher em sua obra, como se aí residisse a única maneira de reconhecer nela um sujeito, nessa ambiguidade que a represente como ser desejante e passível de causar rupturas à norma. De outro modo, conforme Baudelaire mesmo comenta em uma crítica aos quadros de Delacroix, representa-se "a mulher moderna em suas manifestações heroicas, no sentido infernal ou divino" (BENJAMIN, 2003a, p. 56, tradução nossa). Neste sentido, vale tomar nota da leitura que Benjamin faz da representação da figura da mulher em Baudelaire, pois a definição de modernidade perpassa também a relação que se estabeleceu com o feminino e com a entrada, a partir daquele momento, da mulher no mercado de trabalho. Benjamin vê que o poeta foi um dos poucos a perceber a grandeza desse momento e soube condensar e expressar como ninguém os conflitos, crises e mudanças que estavam ocorrendo. A "modernidade em Baudelaire é uma conquista" (BENJAMIN, 2003b, p. 166, tradução nossa) somente realizável naquilo que ele expôs, através de sua vida, sobre as contradições subjacentes entre uma sociedade que se expandia e possibilitava a fetichização e a mercantilização massificadas, e o sujeito, perdido e descentrado em tal contexto: daí 
que "O herói é o verdadeiro objeto de la modernité. [...] é preciso uma constituição heroica para viver a modernidade" (BENJAMIN, 2003a, p. 44, tradução nossa).

Não se deixar levar pela suposta normalidade das mudanças pautadas numa certa noção de progresso - associadas à supervalorização do fetiche da mercadoria sob a égide do valor de troca - é, portanto, uma tarefa hercúlea no processo de subjetivação do sujeito moderno, bem evidenciada na figura do poeta maldito que dedica ao mundo suas flores doentias. Nesse sentido, nas anotações para a redação de sua grande obra incompleta sobre a modernidade parisiense, Benjamin (2003b, p. 170, tradução nossa) observa:

\begin{abstract}
O século dezenove começou abertamente e sem reservas a incluir a mulher no processo de produção de mercadorias. Todos os teóricos estavam unidos na opinião que sua feminilidade específica estava, portanto, sob perigo; características masculinas deveriam necessariamente se manifestar nas mulheres depois de um tempo. Baudelaire afirma essas características; ao mesmo tempo, entretanto, procura libertá-las da dominação da economia. Por isso a ênfase puramente sexual que ele vem a dar a essa tendência de desenvolvimento na mulher. $O$ paradigma da mulher lésbica representa o protesto da "modernidade" contra o desenvolvimento econômico.
\end{abstract}

Aqui, os ideais da revolução francesa e do sonho do indivíduo autônomo se transpõem para a ambiguidade da imposição à mulher, que deveria permanecer em casa cuidando das tarefas domésticas, e a abertura que esses mesmos ideais promovem no que diz respeito à inserção da mulher no campo do trabalho. Se por um lado, havia um discurso que promovia sua inserção no mercado de trabalho - como um sujeito livre e portador de direitos -, por outro havia um discurso inverso que a relegava ao destino do cuidado da vida privada (PERROT, 2009). A mulher masculinizada aparece na poesia de Baudelaire como um protesto contra a ideia de que, por adentrar no mercado de trabalho, passaria a assumir uma imagem negativamente carregada por adotar traços masculinos.

Dessa forma, a respeito do estudo de Benjamin sobre Baudelaire, Neri (2005) cita a afirmação do autor alemão de que, na poesia baudelairiana está formulado, mais do que em qualquer outro crítico da modernidade, que a ruptura com os padrões anteriores e a modernização representam o desmoronamento das identidades sexuais: "Assim, em Baudelaire [...] o mais virulento anti-feminismo, a afirmação viril contra a feminização da cultura se alinha com a identificação com algumas figuras de predileção" (NERI, 2005, p. 80). Essas, já comentadas, seriam mulheres malditas, a prostituta, a lésbica, a andrógina, que "subvertem os papeis sexuais estabelecidos 
pela burguesia e aspiram à revolução sexual” (NERI, 2005, p. 80). Esse protesto, em Baudelaire, se apresenta como o culto às figuras marginais que rompem com a norma; rompimento esse que é, ao mesmo tempo, ambíguo no poeta, tendo em vista que, apesar de repudiá-las em alguns momentos, também com elas se identifica em sua condição marginal, à deriva, como o flâneur que vai contra a multidão.

No que diz respeito à criação da personagem principal do romance "Madame Bovary", de Gustav Flaubert, publicado em 1857, Baudelaire (2011) a referencia como uma heroína que não precisava ser descrita como tal. Contanto que fosse suficientemente bonita, tivesse ambição e um pendor a aspirar por um mundo superior, por uma vida outra que não a sua, ela despertaria interesse nos leitores. O romance, da mesma forma que no caso de "As flores do mal", também resultou em um processo contra o autor por ofender a moral pública, uma vez que sua força literária não era extraída de outra fonte senão do tema que unia a protagonista ao adultério, à traição do marido e à entrega aos desejos carnais. A leitura que Baudelaire faz da personagem central do romance, Emma Bovary, é a de uma mulher com características masculinas ou andróginas, indefinidas na virilidade que se sustenta na aspiração de quem é capaz de imaginar e reconhecer seu desejo, como comenta em resenha da obra, na qual a aclama como uma verdadeira aposta e um risco, seguindo a mesma maneira com que são criadas todas as obras de arte. Sobre Flaubert, argumenta:

Só restava ao autor, para terminar a prova da força por completo, despojarse (tanto quanto possível) de seu sexo e se fazer mulher. Disso resultou uma maravilha; é que, apesar de todo seu zelo de autor, ele não pôde deixar de infundir seu sangue viril nas veias de sua criatura, e a sra. Bovary, para o que há nela de mais enérgico e mais ambicioso, e também de mais sonhador, a sra. Bovary permaneceu um homem. Como a Palas, armada, saída de Zeus, esse andrógino bizarro manteve todas as seduções e uma alma viril em um encantador corpo feminino. (BAUDELAIRE, 2011, p. 13)

O poeta comenta que tais atributos o fazem ver na personagem uma figura sonhadora associada a qualidades viris, elencando, por exemplo, a imaginação, produto da racionalidade, o oposto do que predomina nas mulheres, que seriam guiadas pelo coração; somam-se a isso a energia súbita para ação, característica de homens criados para agir, o gosto imoderado pela sedução, pela dominação, pelo vestuário e perfumes, que remetem ao dandismo, e o fato de Emma Bovary ter sido rejeitada no convento onde estudava devido a sua espantosa aptidão para a vida, para conjecturar sobre a sua felicidade, coisas que seriam masculinas - "eis o homem de 
ação!" (BAUDELAIRE, 2011, p. 14-15). Disso, o poeta conclui que a personagem substituía o Deus verdadeiro pelo Deus de sua fantasia, pelo Deus do futuro e do acaso:

A histeria! Por que esse mistério fisiológico não seria o fundo e a base de uma obra literária, esse mistério que a Academia de Medicina ainda não resolveu e que, exprimindo-se nas mulheres pela sensação de um aperto na garganta, ascendente e asfixiante (falo apenas do sintoma principal), traduz-se nos homens nervosos em todas as fraquezas e também na aptidão para todos os excessos? (BAUDELAIRE, 2011, p. 16)

É inegável que Freud buscou compreender esse modo de sofrer, referido por Flaubert quarenta anos antes do surgimento da psicanálise, mas sua teoria concedeu predominância ao desenvolvimento sexual masculino, tendo a feminilidade um desenvolvimento maior na obra de outros psicanalistas que produziram paralelamente a Freud e comunicavam a ele suas descobertas (FREUD, 1925). Considerando o questionamento de Baudelaire, podemos dizer que Freud foi capaz de perceber que aquela sintomatologia diferia de uma base orgânica ou fisiológica. A psicanálise surge tendo como fundo as crenças básicas da modernidade, como o individualismo e a liberdade, a família nuclear, e a mobilidade social, que por serem importantíssimos à vida coletiva, produziam também formas de sofrimento.

Por essa razão, é visível que a força do sonho da liberdade e de uma "vida outra" que Emma Bovary, protagonista do romance de Flaubert, associado à sua inacessibilidade - determinada por sua condição de ser mulher -, acabou por levá-la à neurose e ao suicídio. Kehl sustenta a tese de que, diferente do homem, Emma não poderia ocupar o lugar que buscava alcançar devido a ter nascido mulher àquela época. Suas possibilidades eram limitadas, e a busca pelo olhar do outro, de tornarse objeto do desejo do outro, se realizaram pelas vias da atuação muito mais do que pela via da conversão. Por isso, homologamente, o paradoxo de Freud se encontra na relação tensa entre a libertação do desejo e de sua normatização (KEHL, 2016). Como vemos com Charchot, no Salpêtrière, quando da ida de Freud a Paris para estudar no departamento de neurologia, essa imagem está marcadamente associada ao fato de que a categorização de seu desejo se dá pela via do profano, da blasfêmia, e que, quando é finalmente reconhecido, isso se dá pela via da individualização e fragmentação. Às histéricas se atribuía, por vezes, a ideia de que estariam sob efeito de alguma ação supernatural ou demoníaca. 
Ainda, relevante de ser lembrado, no campo da produção artística da modernidade, é a figura de Gustav Klimt (1862-1919), precursor e líder da Secessão de Viena. ${ }^{4}$ Vienense como Freud, compartilhou do mesmo período histórico e, ainda que não tenha havido uma relação de proximidade ou de conhecimento um da obra do outro, expressou por outras vias os mesmos anseios culturais, morais e políticos que permeavam a cultura europeia à época. Klimt era uma espécie de metapsicólogo no mundo visual, como Schorske (1988) o descreve, e produziu pinturas em grande proximidade com a epígrafe Flectere si nequeo superos, Acheronta movebo, ${ }^{5} \mathrm{da}$ Interpretação dos sonhos (1900), a qual poderia - da mesma maneira que em Freud - servir de alegoria a sua obra, que apresenta "uma visão que afirma desejo e, ao mesmo tempo, a dissolução mortal dos limites entre ego e mundo" (SCHORSKE, 1988, p. 222).

Klimt, assim como Freud, também possuía grande apreço pela cultura arcaica e pela arqueologia, utilizando-se de "símbolos clássicos como ponte metafórica para a escavação da vida instintiva, e principalmente sexual" (SCHORSKE, 1988, p. 215). Nesse sentido, a figura da mulher aparece em suas pinturas como "criatura sensual, desenvolvendo todo o seu potencial de prazer e dor, vida e morte" (SCHORSKE, 1988, p. 215). A obra de Klimt possui uma vasta quantidade de representações do feminino que se estendem desde a erotização e idealização da mulher, até a ruptura com uma representação realista para a abstração dos significados e do simbolismo. Digno de nota é o fato de que, na primeira metade de sua obra, a mulher é representada de maneira andrógina, em alguns casos masculinizadas, como é evidenciado por Schorske no caso de Palas Atena - figura recorrente em Klimt -, de formas ameaçadoras e potencialmente destruidoras da pretensa masculinidade. Assim, Schorske (1988, p. 216) observa: "Na sua exploração do erótico, Klimt baniu o sentido moral do pecado que atormentara os pais virtuosos. Mas, em seu lugar, surgiu um medo do sexo que assombrou muitos filhos sensíveis. A mulher, como a Esfinge, ameaça o homem".

\footnotetext{
${ }^{4}$ Movimento de vanguarda no fim do século que busca romper as barreiras com as heranças tradicionais na produção artística em busca de uma identidade para a cultura e para o sujeito moderno. O cartaz da primeira exposição da Secessão de Viena, de 1897, produzido por Klimt, representa alegoricamente o mito de Teseu, que mata o Minotauro, remetendo a um rompimento com a ideologia da tradição paterna e com a historicidade clássica que enrijeceria a produção de novas formas de representar e produzir novas significações sobre o sujeito moderno.

5 "Se não posso dobrar os poderes celestiais, agitarei o Inferno". A epígrafe é extraída da epopeia Eneida, de Virgílio, escrita no século I a. C.
} 
Essa aspiração se mostra condizente com o que ocorre, ao mesmo tempo, em um período muito próximo, com a produção literária e poética de Flaubert e Baudelaire, pois em ambos a representação da mulher se dá por esse registro potencialmente destruidor da norma, mesmo que ela não seja ainda legitimada enquanto sujeito de discurso, o que Freud viria a fazer ao começar a escutar suas primeiras pacientes. A Secessão de Viena expressou o estado de anseio pela libertação das estruturas que já estavam se dissolvendo na crise da razão e do homem do esclarecimento, através do lema "À época sua arte, à arte sua liberdade". Todavia, "ao procurar a imagem de Eros doador de prazeres, enquanto segurava o espelho para o homem moderno, Klimt encontrou, ao invés dela, os problemas psicológicos que cercavam a tentativa de libertar a sexualidade das restrições de uma cultura moralista" (SCHORSKE, 1988, p. 217).

Assim, a segunda metade do século XIX é um período de confusão no qual a família não consegue mais situar o indivíduo em um mundo que avança e se transforma rapidamente. "A liberdade, ideal moderno inaugurado com a Revolução Francesa e transformado em direito individual com o estabelecimento da burguesia como classe hegemônica na Europa, cobra o preço do desamparo e do desenraizamento" (KEHL, 2016, p. 29). A esperança de fazer da existência uma aventura pessoal - o indivíduo, novo herói moderno, idealiza um futuro possível, para além da realidade em que se desenvolve e para além dos grilhões que o aprisionam a uma vida determinada do berço à morte, liberta-se da determinação - se torna a norma pelas aspirações da época. O individualismo e a idealização de uma vida distinta, desnudada dos ideais românticos e transposta para a realidade, levam à hipótese da neurotização dos sujeitos frente aos "impasses e demandas conflitantes que incidem sobre o sujeito moderno" (KEHL, 2016, p. 30). O sujeito neurótico nasce junto do sujeito moderno, ambos criados na relação do sujeito com seu tempo, uma vez que não há sofrimento psíquico desvinculado do tempo que se vive e das formas de subjetivação marcadas culturalmente pela relação com o social.

A família nuclear aparece, portanto, como o espaço no qual, em oposição à vida pública da cidade, os sujeitos podem se sentir, finalmente, à vontade. O casamento burguês, para a mulher da época, como comenta Kehl (2016), não é entre a mulher e seu marido, mas entre a mulher e o lar. A mulher, ao ficar excluída da vida pública, ainda assim é influenciada pela lógica individualista que constitui seu tempo, vendose no meio do impasse de sonhar com uma realidade distinta e se ater aos afazeres 
domésticos. São justamente os ideais modernos que promovem a possibilidade da emancipação, da circulação no mundo do trabalho e da luta por direitos sociais por parte das mulheres. São eles que, se por um lado trariam aspectos benéficos, por outro, como ocorreu não deixa de ocorrer com os homens, produziriam novas formas de sofrimento.

Contudo, a situação de opressão da mulher não surge e nem se restringe à sociedade moderna. Esse é o período em que o capitalismo ganha corpo determinando os modos de circulação de bens e de distribuição de riquezas, tornandose o modelo hegemônico e vinculado à transformação das relações sociais. Não obstante, em diferentes contextos e períodos históricos a mulher foi oprimida, não estando necessariamente vinculado ao modelo burguês da modernidade. Há um elemento moral e histórico em torno do qual o patrimônio cultural de formas de feminilidade e masculinidade se reproduzem, onde o domínio do sexo e a opressão sexual se encontram. Diante disso, ainda que a cultura burguesa tenha intensificado padrões de opressão de um sexo sobre o outro, ela não é a razão pela qual essa opressão surge (RUBIN, 2017). A validade, portanto, de relacionar a cultura patriarcal vienense e europeia ao período do capitalismo liberal, não se deve tanto ao fato de que a partir dele se explicaria, finalmente, os dispositivos que formularam a opressão da mulher, mas que a partir do capitalismo e do advento do indivíduo moderno a descrição e a percepção sobre a mulher ganha diferentes matizes. Nesse ponto, o interessante é justamente mostrar o quanto a modernidade, a partir da revolução cultural, econômica e dos modos de relação social vividas no século XIX, é também a era onde a psicanálise surge com Freud, e que essa revolução de costumes foi fundante de um modo de sofrimento condicionado, determinado e qualificado pelo ideal da realização de uma vida distinta, promovida por alguns exemplos de transformação social mostrados acima.

\section{Complexo de Édipo e Sexualidade Feminina}

O fracasso da ciência do século XIX em solucionar os sintomas dos quais as mulheres padeciam prepara o surgimento da psicanálise. Freud dá início a investigações que buscavam uma base psíquica aos sintomas das histéricas, inaugurando uma verdadeira revolução epistemológica. A égide da razão dá espaço ao profundo e desconhecido oceano do inconsciente; a sintomatologia descritiva e a 
psicopatologia biológica são sobrepostas por uma compreensão mais abrangente da experiência humana.

Disso decorrem alguns questionamentos que são válidos a quem investiga o conceito de feminilidade na obra de Freud, pois apesar de ter legitimado e reconhecido o desejo feminino - com repercussões em todo o século $X X$ - paradoxalmente reproduziu as mesmas estruturas denunciadas por ele sobre o desejo feminino (KEHL, 2016). Freud teria contribuído para o tratamento de inferioridade dado às mulheres ao se referir a conceitos como a inveja do pênis e buscado legitimar o falocentrismo dentro de sua obra? Estaria reproduzindo a estrutura patriarcal da qual sua leitura do psiquismo é tributária? A que tipo de feminilidade Freud recorre para descrever os destinos do Édipo na mulher em seus textos tardios?

Há um notável esquecimento sobre a sexualidade feminina ao longo da obra de Freud, que inúmeras vezes supôs que a psicologia da mulher poderia ser vista simplesmente como análoga a do homem. Essa é a opinião de Stratchey (1961, p. 262) acerca da interpretação de Freud sobre a sexualidade feminina. No entanto, os textos centrais sempre têm alguma relação com esse aspecto: Freud alertou que a descrição do desenvolvimento da sexualidade das mulheres era ainda um dark continent - referência a esse problema teórico não resolvido (FREUD, 1926/1976, p. 199) - e suas tentativas de desenvolver uma teoria que contemplasse a sexualidade feminina, e, por conseguinte, a feminilidade, apareceram somente ao fim de sua obra.

A expectativa de que houvesse um paralelo entre o complexo de Édipo no menino e na menina se mostrou, desde "Três ensaios sobre a teoria da sexualidade" (1905), difícil de se concretizar, dada sua tese de que inicialmente predominaria a fase fálica na menina, através do clitóris, e somente depois seria direcionada à organização genital infantil com o predomínio da genitalidade. A isso se acrescentava uma distinção evidente, baseada na escolha de objeto da mulher, que deveria ser substituído, voltando-se da mãe para o homem em um determinado momento de seu desenvolvimento. Contudo, essa solução parcial se manteve, e desde o Caso Dora, como comenta Strachey (1961, p. 263), seu interesse não se dirigiria à psicologia feminina por um longo tempo.

O discurso científico da época na qual tal teoria foi gestada, assim como os discursos literário e estético propunham, no campo da mulher, um silenciamento do seu desejo sexual. Quando reconhecido, esse desejo assumia a forma de uma masculinização ou androginia. No entanto, é visível que mesmo nas publicações pré- 
psicanalíticas, antes de Freud ter escrito a Interpretação dos sonhos (1900) ou os "Estudos sobre a histeria" (1895), já se esboçava que a razão pela qual as mulheres desenvolveriam alguma enfermidade histérica seria de ordem funcional, isto é, relativa à vida sexual: "[...] se debe admitir que unas constelaciones funcionales relativas a la vida sexual desempeñan un gran papel en la etiología de la histeria (así como de todas las otras neurosis), y ello a causa de la elevada significatividad psíquica de esta función, en particular en el sexo femenino. El trauma es una causa ocasional frecuente de afecciones histéricas [...]" (FREUD, 1888/1976, p. 56).

Nas "Novas conferências introdutórias à psicanálise" (1933), no texto dedicado à feminilidade, Freud contrapõe a investigação psicológica ao determinismo biológico. Afirma que não se pode pressupor que, em razão da existência de uma relação determinada biologicamente de atividade-passividade entre os sexos, demonstrada a partir dos "organismos sexuais elementares ${ }^{6 "}$, as relações de conduta vão estar determinadas desse modo desde o princípio. É um erro identificar o masculino a uma conduta ativa e o feminino a uma conduta passiva, comenta ele. Quando se trata de psiquismo, o que Freud quer dizer aqui, é que não se determinará de forma alguma o desenvolvimento sexual somente pelo aspecto orgânico e biológico. Ele caracteriza a feminilidade por uma "preferência" por metas passivas; é aos destinos da pulsão que dá relevância, e estes não se excluem do campo da cultura a partir do momento que a cria humana é introduzida nele.

Isso é visível na afirmação de que a mulher pode derivar, da função sexual, uma posição passiva que se estende em maior ou menor grau para toda sua vida. Freud afirmará que o masoquismo estaria muito mais intimamente ligado à posição feminina e passiva. Contudo, não se pode excluir dessa inclinação o campo do social, que também seria produtor desse masoquismo. Daí que quando fale sobre o masoquismo, ou sobre passividade-atividade, esteja a falar de características, de funções, ao contrário de uma relação determinista com o sexo biológico:

[...] debemos cuidarnos de pasar por alto la influencia de las normas sociales, que de igual modo esfuerzan a la mujer hacia situaciones pasivas. Todo esto es todavía muy oscuro. No descuidaremos la existencia de un vínculo particularmente constante entre feminidad y vida pulsional. Su propia constitución le prescribe a la mujer sofocar su agresión, y la sociedad se lo impone; esto favorece que se plasmen en ella intensas mociones masoquistas, susceptibles de ligar eróticamente las tendencias destructivas

\footnotetext{
${ }^{6}$ Freud (1933, p. 106) aqui trata da questão da célula masculina, comenta que "la célula genésica masculina se mueve activamente, busca a la feminina, y el óvulo permanece inmóvil, aguardando de manera pasiva".
} 
vueltas hacia adentro. El masoquismo es entonces, como se dice, auténticamente femenino. Pero si, como ocurre con tanta frecuencia, se topan ustedes con el masoquismo en varones, ¿qué otra cosa les resta si no decir que estos varones muestran rasgos femeninos muy nítidos? (FREUD, 1933/1976, p. 107-108, grifo nosso)

Vale notar também que Freud ressalta a importância da bissexualidade na menina, que se encontra mais presente do que no menino. A bissexualidade, segundo Freud (1931), é uma disposição constitucional que nos primórdios do desenvolvimento do complexo de Édipo se vê muito latente, possuindo um duplo sentido, ativo e passivo. Observa também em "Algumas consequências psíquicas da diferença anatômica entre os sexos" (1925), que é só com o ingresso na cultura e com a emergência do Supereu que será direcionada à orientação compulsoriamente heterossexual.

O que importa ressaltar aqui é que, no desenvolvimento da sexualidade feminina, a relação que a menina mantém com a mãe na fase pré-edípica se torna mais importante para seu desenvolvimento psíquico do que a relação posterior com o pai. Como afirmará Freud (1925), é no mais distante período da infância que pode se lançar luz sobre questões obscuras para a psicanálise. Em um texto tão importante como os "Três ensaios sobre a teoria da sexualidade" (1905), Freud reconhece que sua teoria é escassa na questão da sexualidade feminina, "envuelta em uma obscuridad todavía impenetrable" (FREUD, 1905/1976, p. 137). Nesse momento o monismo sexual, baseado na formulação da libido única e do complexo de Édipo este visto desde o ponto de vista da falta do pênis ou de sua posse, sem antes relevar que esse pênis é a representação do falo - é o que predomina na teoria freudiana. Posteriormente, a partir de 1923, Freud revisitará este aspecto propondo que o dilema se explicita na relação que a criança possui com a castração e o falo. Aí é que dará alguma resposta às indagações que fazia sobre os destinos da sexualidade da menina, que não poderiam ser nem análogos aos do menino, nem simplesmente seu inverso.

Uma questão central é sobre em que momento desse mais período distante do desenvolvimento sexual - e mediante que condições - a menina deixa de ter como objeto amoroso a mãe e passa a adotar o pai como objeto de investimento. Freud comenta que "inicialmente la madre fue para ambos el primer objeto, y no nos asombra que el varón lo retenga para el complejo de Edipo. Pero, ¿cómo llega la niña a resignarlo y a tomar a cambio al padre por objeto?" (FREUD, 1925/1976, p. 270). Seria 
a partir da descoberta feita pela menina de sua condição de faltar-lhe o pênis que passaria a sentir inveja da condição daqueles que o possuem. "Ella nota el pene de un hermano o un compañerito de juegos [...] y al punto lo discierne como el correspondiente, superior, de su propio órgano, pequeño y escondido; a partir de ahí cae víctima de la envidia del pene." (FREUD, 1925/1976, p. 270). No menino é a percepção de que pode, em algum momento, deixar de possuir o suposto representante de sua superioridade em relação a quem não o tem, que se desdobra em aversão à menina, que é vista como "mutilada", sob "um triunfante menosprezo". O temor que o toma por completo faz com que a dissolução do complexo de Édipo tenha início. Na menina, isso ocorre de outro modo: "há visto eso, sabe que no lo tiene, y quiere tenerlo" (FREUD, 1925/1976, p. 271). Sucede-se, portanto, aquilo que Freud chamará de complexo de masculinidade, que deverá ser superado em seu desenvolvimento psíquico. Se a menina permanecer tendo a esperança de ter um pênis, isso resultará em atos peculiares ou numa desmentida que a leve a se sentir compelida a agir como um homem. Freud antecede assim as teses que iria esboçar em "A feminilidade" (1933) e "Sobre a sexualidade feminina" (1931), ainda que, aqui, de maneira incompleta.

Se a menina renuncia à possibilidade de ter o pênis, delega a culpa de sua condição à mãe, que a colocou no mundo dessa maneira. Desvincula-se para tanto da mãe, e toma o pai como objeto amoroso, substituindo o desejo de possuir um pênis pelo desejo de ter uma criança, e renunciando, também, à sexualidade clitoridiana e à fase fálica. Entra, portanto, se não encontrar problemas a esse destino, no caminho em direção à feminilidade. O complexo de Édipo na menina não sucumbe como ocorre no menino - quando este descobre a diferença sexual e a punição imaginária que alguns receberam, o qual Freud chama de complexo de castração - mas é uma formação secundária introduzida pelo complexo de castração. A menina, à sua maneira, irá buscar no pai aquilo que sua mãe não pôde lhe dar. (FREUD, 1925).

Em fase posterior, a obra freudiana toma como aspecto importante a noção de "repúdio à feminilidade", descrito como uma atitude frente ao complexo de castração. Em "Análise terminável ou interminável" (1937), Freud propõe que tal atitude não ocupa a mesma posição em ambos os sexos. Nos homens o esforço em tapar a castração está de acordo com as aspirações do Eu, e sua aceitação é energicamente reprimida; nas mulheres o esforço em encobrir a castração seria visível na fase fálica 
e posteriormente a feminilidade seria adotada dependendo dos destinos que a mulher dará a seu desejo.

Como exposto em "A feminilidade" (1933), haveria três destinos para a sua sexualidade: 1) a busca pelo falo através do bebê, com a qual daria entrada no Édipo e completaria sua "predestinação" biológica e social; 2) uma postura pretensamente masculina e de encobrimento de seu destino; 3) ou a frigidez e a negação completa de sua sexualidade. Ou seja, da mulher se esperaria que cumprisse o papel de compensar sua castração através da criança, do bebê, cumprindo sua função social, e o desvio dessa norma enveredaria pelos caminhos da patologia. De outro modo, a histeria se evidenciaria nesse contexto como a marca do complexo de Édipo que não resultou em uma destinação "saudável".

A percepção de que a falta do pênis resultaria em um sentimento de inferioridade da mulher pode soar assombrosa, mas a constatação evidencia, antes, a estrutura de poder que delimita dentro de um quadro possível formas de sexualidade que são permitidas e outras que não são permitidas. Para as mulheres haveria um caminho predestinado, cujo desvio resultaria em adoecimento na vida futura. Vale lembrar que essa descrição de como a sexualidade feminina se estrutura está condicionada a partir da perspectiva das crianças e de suas reações a um formato universal do complexo de Édipo e do complexo de castração. Ainda que muitas críticas de feministas a Freud sejam justificadas, é preciso recordar que o que Freud descreve é o pensamento e a simbolização possível no nível das crianças em idade edipiana.

Não se pode deixar de atentar, portanto, ao fato de que a escassa capacidade de compreensão das crianças frente à percepção da diferença anatômica entre os sexos dá origem a diversas teorias sexuais infantis; tentam construir uma explicação para esse fenômeno, resultando em teorias que explicitam o formato das relações sociais, o poderio da figura paterna e, imaginariamente, o pênis - falo - como representante de algum poder em razão da diferença entre os sexos. Um dos problemas inerentes à capacidade de simbolização das crianças nessa idade, segundo a concepção freudiana, é a noção da existência de um único sexo, representado este pela presença do pênis, significando assim, a sua ausência, uma falta, e não a admissão imediata da existência de outro órgão genital - e de outro sexo. É esse modo peculiar do pensar infantil que Freud denomina de lógica fálica. Como adverte Freud em "A organização genital infantil" (1923), isso não diz respeito ao primado dos genitais; o que está posto não é o aspecto material e concreto do 
pênis, mas a primazia do falo. "El carácter principal de esta «organización genital infantil» es, al mismo tiempo, su diferencia respecto de la organización genital definitiva del adulto. Reside en que, para ambos sexos, sólo desempeña un papel un genital, el masculino. Por tanto, no hay un primado genital, sino un primado del falo" (FREUD, 1923, p. 146, grifo nosso). O que Freud parece apontar nesse texto é que a diferença anatômica não é vista como oposição entre um genital masculino e outro feminino, mas entre presença e ausência, entre um genital masculino e um castrado. Isso, evidentemente, ocorre na percepção das crianças. Apenas ao se completar o desenvolvimento, na puberdade, que haverá a organização genital em direção ao masculino e feminino.

\section{Gênero, Diferença Sexual e a Relação de Freud com o Feminino}

No momento em que as crianças descobrem o tabu do incesto e a proibição de aspectos de sua sexualidade, também descobrem algumas informações desagradáveis sobre o gênero que lhe atribuem. A respeito da menina, Rubin afirma que não é por uma superioridade natural do pênis que ela chega a essa ideia. " $A$ disposição hierárquica dos órgãos genitais masculinos e femininos vem de definições da situação - a regra da heterossexualidade obrigatória e a relegação das mulheres (aquelas que não tem o falo, castradas) aos homens (aqueles que têm o falo)" (RUBIN, 2017, p. 45). O interesse da autora aqui, em sua crítica a Freud, é de relacionar a teoria da psicanálise com a antropologia estrutural de Levi-Strauss, que promove a compreensão de que o início da cultura se dá pela razão do tabu do incesto e das relações elementares de parentesco. Para a autora, ambos convergem, Freud e LeviStrauss, ao mesmo ponto, por caminhos distintos - o de que a sexualidade humana não é natural, e a heterossexualidade compulsória é produto cultural, antes de ser naturalmente posta como a investigação científica da época levaria a crer.

A leitura das relações que ocorrem na estruturação da identidade de gênero e da orientação sexual na obra em Freud são tributárias da época em que foram escritas, como já dito. Mas essa constatação não nos tira da necessidade de repensarmos os pressupostos denunciados por Freud na possibilidade de libertação do destino unívoco e potencialmente destrutivo à mulher. Rubin comenta que o problema no que diz respeito à teoria e à prática clínica, ainda que tenha sido esboçado de diversas maneiras por meio das críticas feministas da metade do século passado, é justamente o fato de que, apesar de serem libertadoras em vários 
aspectos, agiram sobre o social de maneira a normatizar e a enquadrar os sujeitos dentro de um desenvolvimento psíquico "normal" e "saudável". No entanto, como observa Mitchell (apud RUBIN, 2017, p. 36): “É impossível ignorar, no estudo das mulheres, os métodos de uma ciência do psiquismo, uma teoria que tenta explicar como as mulheres se tornam mulheres e os homens, homens. O limite entre o campo biológico e o campo social, que encontra expressão na família, é o terreno mapeado pela psicanálise, o terreno em que a diferença sexual se origina."

$\mathrm{O}$ aspecto visionário da psicanálise se efetivou de tal forma que acabou se tornando refém das próprias estruturas que visava explicitar na formação do sujeito. A clínica, por sua vez, sofreu críticas de ser mais um dispositivo que busca reproduzir e perpetuar as estruturas que ela mesma lia como formadora dos sintomas. Desses pontos decorre boa parte da crítica feminista que se estendeu ao longo da segunda metade do século passado, e que Rubin (2017) busca retratar no ensaio "O tráfico de mulheres". No entanto, a autora afirma que "a psicanálise é uma teoria feminista que não chegou a se configurar plenamente como tal" (RUBIN, 2017, p. 36). Nesse ensaio, influente no meio acadêmico e nos debates feministas da década de setenta, Rubin defende a tese de que a obra de Freud demarca formas de produção de "sexualidades" em uma cultura que normatiza a opressão. A autora afirma que a obra freudiana, em sua teoria da aquisição de gênero, vai somente até certo ponto e deixa de realizar seu potencial, que seria o de uma crítica dos papeis sexuais, já que pôde esboçar como se constitui o sujeito. Silenciar diante do surgimento do feminismo, e repudiá-lo, é uma negação dos próprios pressupostos fundantes da leitura da sexualidade humana e da constituição do sujeito. Portanto, para Rubin (2017, p. 39):

\begin{abstract}
Freud nunca chegou a ser tão determinista do ponto de vista biológico com reivindicariam alguns. Ele enfatizou repetidamente que qualquer forma de sexualidade adulta resulta de um desenvolvimento psíquico, e não biológico. Mas seus escritos são muitas vezes ambíguos, e suas formulações deixaram margem para interpretações biológicas que vieram a se tornar tão populares na psicanálise americana. Na França, por outro lado, a tendência da teoria psicanalítica foi a de desbiologizar Freud [...] Jacques Lacan, que esteve na origem dessa linha de pensamento, argumenta que Freud nunca teve a intenção de dizer nada a respeito de anatomia, que a teoria de Freud tratava, na verdade, da linguagem e dos significados impostos à anatomia.
\end{abstract}

Cabe referir, em relação ao tema da sexualidade feminina exposto acima, aquilo que Freud escreve em seu texto sobre a feminilidade, de 1933: "[...] el psicoanálisis, por su particular naturaleza, no pretende describir qué es la mujer una tarea de solución casi imposible para él —, sino indagar cómo deviene, cómo se 
desarrolla la mujer a partir del niño de disposición bissexual" (FREUD, 1933/1991, p. 108). Apesar de que o reconhecimento dessa trajetória constitutiva e determinada culturalmente foi feita por Freud, Rubin (2017) afirma que o caminho à feminilidade, nas mulheres, é um ato de violência psíquica que deixa como resquício um enorme ressentimento às supressões a que foram submetidas. Além disso, observa que os textos de Freud sobre a feminilidade podem ser lidos como descrições de como se prepara psicologicamente desde a infância das mulheres para viverem com a própria opressão. Sobre as críticas feministas, comenta que, na medida em que a teoria psicanalítica é uma racionalização da subordinação das mulheres, elas têm se justificado. Mas como explicação de como o tipo de cultura em que ela mesma foi criada domestica as mulheres, continua incomparável. Por isso a autora observa que tanto Lévi-Strauss como Freud elucidam aspectos das estruturas que geraram profunda opressão sexual, e que se não fosse por eles, jamais seriam percebidas: "suas contribuições nos fazem lembrar da intratabilidade e da magnitude daquilo contra o que lutamos" (RUBIN, 2017, p. 49). Apesar de Freud não contestar o sexismo bastante evidente - olhando retrospectivamente - na cultura em que vivia, os questionamentos e leituras feitas por ele foram de suma importância para os estudos posteriores sobre gênero e sobre a constituição do sujeito no campo da filosofia.

Nesse sentido, vale notar que em "O futuro de uma ilusão" (1927) Freud comenta sobre a tese do neurologista Paul Julius Moebius, que atribuía às mulheres uma "debilidade mental fisiológica", o que significa dizer que às mulheres aspectos que correspondessem à inteligência e a possibilidade de serem sujeitos intelectuais estariam de fora das suas realizações, devido uma base inata e orgânica. Freud indica um aspecto secundário, social, dessa suposta incapacidade que, afinal, corresponderia a todos os sujeitos:

[...] se dice y se repite que las mujeres en general sufren la llamada
«imbecilidad fisiológica», es decir, tienen menor inteligencia que el varón. El
hecho mismo es discutible, su explicación es incierta, pero he aquí un
argumento que indicaría la naturaleza secundaria de esta mutilación
intelectual: las mujeres están sujetas a la temprana prohibición de dirigir su
pensamiento a lo que más les habría interesado, a saber, los problemas de la
vida sexual. Puesto que desde muy temprana edad pesan sobre el ser
humano, además de la inhibición de pensar el tema sexual, la inhibición
religiosa y, derivada de esta, la de la lealtad política, de hecho nos resulta
imposible decir cómo es él realmente. (FREUD, 1927/1976, p. 47)

Freud se opôs a essa ideia de Moebius, mas mesmo que dentro do campo da teoria e da clínica isso tenha sido claro para ele, a relação que a ciência estabeleceu 
com o discurso sobre a mulher, ainda em sua época - e isso já seria década de vinte quando da frase acima citada - foi uma de negligência e esquecimento, algo que se repetiu por algum tempo em sua obra. É inegável, como Rubin (2017) observa, que a obra de Freud foi libertadora em diversos aspectos no que tange ao sexo feminino, mas Freud foi um cientista que teve a base de sua formação numa lógica positivista, pautada por uma ideia de neutralidade e objetividade nas descrições. As influências do período aparecem nesse sentido pela dificuldade que o próprio campo da ciência conferia à possibilidade de pensar a sexualidade para além de um determinismo biológico. Como observa Neri (2005, p. 188):

\begin{abstract}
O monismo fálico, construção teórica que tem por objetivo pensar a diferença sexual fora do registro do determinismo biológico, acaba por reduzir o feminino à maternidade, mantendo-se assim em continuidade com a tese essencialista com a qual pretendia romper. $O$ tornar-se mulher, que pretende apontar para o feminino como construção, converte-se em ser mãe, como a única garantia de uma especificidade feminina.
\end{abstract}

Dessa forma, os sintomas aos quais Freud pôde dar consistência por meio de sua nosografia - para além do simples tratamento fisiológico e da resignação diante de sua incompreensão etiológica - vieram a constituir um paradoxo: o surgimento da clínica psicanalítica e, por outro lado, a incompreensão de Freud frente ao suposto enigma feminino, que reiteradas vezes se utilizava para descrever as mulheres. Curiosamente essa incompreensão não se devia, hoje é evidente, a uma incapacidade intelectual de Freud para compreender que estava, já naquele momento, contribuindo junto para o discurso feminino e possibilitando que as mulheres escutadas se tornassem sujeitos para além de um destino imposto. Como Kehl (2016) observa, a manutenção desse ponto enigmático em relação ao desejo feminino, esse continente negro da psicanálise, seriam, portanto, o recurso para negar algo que o autor já tinha como sabido, o fato de "que a diferença fundamental entre homens e mulheres é tão mínima que não há mistério sobre o 'outro' sexo a que um cavalheiro não pudesse responder indagando a si próprio" (KEHL, 2016, p. 154). Portanto, se Freud se recusava a reconhecer que para as mulheres a diferença sexual não estava entre uma natureza mística e insondável, enigmática - mas nos discursos sociais que produziam e a sustentavam formatos de vida e de sofrimento que não permitia o reconhecimento de uma relação de caminhos e possibilidades iguais devido à distinção dos papeis entre o público e privado - isso se deve à constatação de que mesmo Freud - como qualquer neurótico - possuía aspectos de si que desconhecia (KEHL, 2016). 
Nesse sentido, na entrada sobre a mãe de Freud no Dicionário de Psicanálise, Roudinesco e Plon observam que Amalia Freud era uma mulher bela e de grande vitalidade, egocêntrica e tirânica com as filhas, e possuía um vasto amor e uma relação privilegiada com seu filho, a tal ponto de posteriormente Freud dizer que era 0 "preferido". Ferenczi, em 1930, enfatizou que a doutrina freudiana da sexualidade devia muito à relação entre Amalia e seu filho: "Nota-se a leviandade com a qual sacrifica os interesses das mulheres aos pacientes masculinos. Isso corresponde à orientação unilateral, andrófila, de sua teoria da sexualidade. Nesse ponto, ele foi seguido por todos seus alunos, inclusive eu [...]" (apud ROUDINESCO; PLON, 1998, p. 257).

Ferenczi havia percebido o esquecimento da teoria da sexualidade feminina na obra de Freud, e buscava razões em sua história para que tal esquecimento decorresse: "É possível que o autor tenha uma repugnância pessoal por uma sexualidade espontânea da mulher, pela orientação feminina: idealização da mãe" (apud ROUDINESCO; PLON, 1998, p. 257). São palavras fortes, mas que denunciam a relação complicada com o feminino que Freud veio a ter durante sua vida, da mesma forma que o biógrafo Peter Gay (1989) também percebe. Roudinesco e Plon observam que "É menos o monismo sexual (libido única) de sua teoria que revela o medíocre conhecimento que Freud tem da feminilidade do que a incapacidade, como disse Ferenczi, em que ele se encontrava de enfrentar a sexualidade da mulher [...] Em relação à sexualidade, Freud adotou em sua vida uma atitude contrária à que preconizava em sua teoria" (ROUDINESCO; PLON, 1998, p. 257). Decorre desse ponto, segundo os autores, a relação que Freud possuiu com sua esposa, destinada a cumprir sua "função natural", cuja sexualidade se reduzia à procriação, nunca tendo de sua parte o apreço que dedicava às questões tidas como masculinas, como o intelecto.

No texto "A feminilidade" (1933), Freud reconhece a incompletude de seu trabalho acerca dos componentes psíquicos da feminilidade, tendo em vista que seu retrato da mulher é eminentemente determinado pela sua função sexual. Assim, decorre sua sugestão de que se busque mais sobre a feminilidade nas nossas próprias vivências ou, principalmente, que possamos nos dirigir aos escritores, pois, como afirma, se alguma característica da mente humana pôde ser desvendada através da ciência, isso se deve a que muito antes algum poeta ou escritor a descreveu no campo das obras de arte. 


\section{CONSIDERAÇÕES FINAIS}

Como a psicanálise se funda sobre dois enigmas, o do inconsciente e o do corpo, a histeria aparece, no fim do século XIX, como sua pedra fundante. É dali que Freud extrai boa parte de suas investigações iniciais e assenta as bases para sua teoria do psiquismo humano. O feminino é um dos pontos de partida da psicanálise, e sua legitimação criou novas formas de pensar as estruturas sociais, liberando do obscurantismo metafísico os pressupostos da inferioridade da mulher. Se a feminilidade foi um conceito, como vimos, de segundo plano na obra freudiana, que tomou contornos mais definidos somente nos textos tardios, ela também veio a ser estudada ao longo do século XX não só no campo da psicanálise, mas nas artes e na literatura. Na sequência do alarido cultural que a psicanálise produziu na cultura europeia, os vanguardistas da contracultura se utilizaram de seus pressupostos para fundar formas outras de representar a produção intelectual e artística. Assim, o movimento surrealista desponta na França à década de 20, influenciado pelo dadaísmo e pelo simbolismo, fazendo uma retomada das ideias do inconsciente freudiano e de suas representações oníricas. A prosa modernista, da mesma forma, com o fluxo de consciência e a escrita automática, é também tributária da escavação da mente humana, produzindo significações sem que elas passassem por uma reflexão intelectualizada que suprimiria sua potencialidade estética. Breton, ao escrever um dos manifestos surrealistas, exalta a figura da histérica como a libertadora de todas as limitações da mente, e por consequência, do desejo humano. Afirma que a histeria foi a descoberta poética do século XIX (MORAES, 2012).

Quando Freud (1937), em seu texto sobre o fim da análise, ponderava as possibilidades de "cura" e os indicadores de que o processo terapêutico havia chegado a seu fim - fim este sempre marcado por sua temporalidade não linear e circunstancial, pela experiência singular do sujeito que elabora e ressignifica seu passado considerava justamente qual tipo de demarcação discursiva ou mudança subjetiva poderia significar o tempo de finalizar pela melhoria nas condições de sofrimento. Talvez pensasse como o sujeito pode deixar sua posição neurótica por uma relação subjetiva que não fosse tão marcada pela busca pelo falo, que é sempre falha em razão de que não pode haver qualquer chance de que essa falta imaginária seja preenchida na vida humana. Todos os gestos que tentam apreendê-lo falham justamente porque ninguém pode sê-lo ou tê-lo, restando somente ser habitado pela 
possibilidade da linguagem para lidar como o impasse da falta, desse rombo que 0 significante produz no homem e que se traduz no desejo de reaver o objeto perdido.

Se o significante feminino se mostrava pela via da aceitação da castração e pela adoção de uma postura passiva para com a vida, isso se deve, principalmente, ao fato de que construção da mulher, gênero portador de características marcadas temporalmente, foi feita predominantemente pelo registro do homem. O discurso da mulher, até o fim do século XIX, havia sido feito a partir do registro masculino, suas possibilidades de expressão de si eram limitadas e, até então, condenadas social e institucionalmente. A mudança nesse curso, que acabou por despontar no século XX como grande móvel de transformações sociais, não se esboça num ato passivo nem resignado. Associar, sem críticas e univocamente, o feminino à passividade, à receptividade, a uma postura menos rigorosamente fálica, é, via de regra, produzir sobre ele novamente aquilo que sempre foi feito, repetir o mesmo erro que se arrasta nas relações desiguais de gênero.

Este artigo buscou compreender as injunções históricas dessa construção através de alguns discursos de vanguarda, aos quais a psicanálise se associa, para ver, paradoxalmente, ainda que diante de todas essas contribuições, as resistências à sua aceitação. Ainda hoje essas resistências são visíveis, mesmo depois de um século do efeito cultural da psicanálise rondar permanentemente a civilização. Onde se esperaria, quiçá ingenuamente, que tais avanços fossem aceitos, o que se vê é a constante tensão que demanda permanentemente a potência das teorias críticas sobre o sujeito, sobre o campo social e como prática clínica. Se o gênero é visto de maneira "ideológica" - como se alguma coisa não o fosse - a psicanálise que o desvela e traz à luz a construção da sexualidade como não-natural e não-instintiva, também se vê atacada por discursos reacionários respaldados pela crise educacional cada vez mais brutal que vivemos.

Foram aqui referidos autores que trabalharam sobre a experiência da modernidade, da qual Freud foi contemporâneo, para chegar à constatação de que o período do século XIX apresenta transformações radicais nas estruturas sociais e nas relações entre os sexos que trariam ao primeiro plano o debate sobre a igualdade e a busca pela emancipação. Percebeu-se que as mulheres que reivindicavam caminhos distintos ao destino da família nuclear burguesa eram vistas como ameaçadoras à masculinidade, evidenciando justamente alguns dos impasses da modernidade. Esses ideais, ao passo que propunham a liberdade individual, também limitavam em vários 
aspectos a vida dos indivíduos. Os conflitos sociais são radicalmente evidenciados no descompasso em que essas mudanças vão ocorrendo, adquirindo contornos específicos nos sintomas histéricos aos quais a psicanálise, como prática de escuta, pôde dar vazão e legitimar. Existe uma relação direta com o ideal do indivíduo moderno e o surgimento da sintomatologia neurótica, o que nos mostra que os modos de sofrimento e as patologias do campo psíquico estão delineadas por experiências temporalmente marcadas, e não puramente orgânicas e biológicas como o discurso hegemônico atual nos quer fazer crer.

Dessa forma, Baudelaire, Flaubert, e Klimt expressam, ainda que do ponto de vista masculino - problema sabido, mas que não tolda a relevância de suas obras no século XIX, nem sua influência no imaginário social e cultural - alguns aspectos sobre o feminino que marcaram sua época. No campo da poesia lírica simbolista de Baudelaire, as figuras marginais e a homossexualidade feminina; em Flaubert a mulher que se imaginava outra e sonhava com outras possibilidades; em Klimt a imagem da mulher masculinizada ameaçadora que poderia fazer soçobrar todos os ideais de masculinidade fragilmente assentados sobre a constituição do homem moderno. Daí que em Freud a mulher também apareça nessa relação de difícil apreensão, retomada em diversos momentos de sua obra, vítima de um certo esquecimento, delineada em meio a um conflito incerto entre um determinismo essencialista sobre o sujeito, que é menos importante, e uma percepção revolucionária no campo do sujeito no que diz respeito à sua constituição e sua sexualidade. 


\section{REFERÊNCIAS}

ADORNO, Theodor; HORKHEIMER, Max. Dialética do esclarecimento: fragmentos filosóficos. Rio de Janeiro: Zahar, 1985.

BAUDELAIRE, Charles. Madame Bovary por Gustave Flaubert. In: FLAUBERT, Gustave. Madame Bovary: costumes de província. São Paulo: Penguin Classics Companhia das Letras, 2011. p. 7-19.

BAUDELAIRE, Charles. O pintor da vida moderna. In: BAUDELAIRE, Charles. Baudelaire: poesia e prosa. Rio de Janeiro: Nova Aguilar, 2006. p. 851-881.

BENJAMIN, Walter. The Paris of the Second Empire in Baudelaire. In: Selected writings: 1938-1940, v. 4. Cambridge: Harvard University Press, 2003a. p. 3-94.

BENJAMIN, Walter. Central Park. In: Selected writings: 1938-1940. v. 4. Cambridge: Harvard University Press, 2003b. p. 161-199.

FREUD, Sigmund. Obras completas Sigmund Freud. 2. ed. Buenos Aires: Amorrortu, 1976.

FREUD, Sigmund. (1888). Histeria. V I.

FREUD, Sigmund. (1895). Estudios sobre la histeria. V. II.

FREUD, Sigmund. (1900). La interpretación de los sueños. V. IV.

FREUD, Sigmund. (1923). La organización genital infantil (1923). V. XIX.

FREUD, Sigmund. (1925). Algunas consecuencias psíquicas de la diferencia anatómica entre los sexos. V. XIX.

FREUD, Sigmund. (1926). ¿Pueden los legos ejerces el análisis? V. XX.

FREUD, Sigmund. (1927). El porvenir de una ilusión. V. XXI.

FREUD, Sigmund. (1931). Sobre la sexualidad femenina. V. XXI.

FREUD, Sigmund. (1933). La feminidad. V. XXII.

FREUD, Sigmund. (1937). Análisis terminable e interminable. V. XXIII.

GAY, Peter. Freud: uma vida para nosso tempo. São Paulo: Companhia das Letras, 1989.

GOLEMAN, Daniel. Freud's mind: new details revealed in documents. The New York Times, nov. 1985. Disponível em: <https://www.nytimes.com/1985/03/17/magazine/new-insightsinto-freud.html>. Acesso em: 23 maio 2020.

KEHL, Maria R. Deslocamentos do feminino: a mulher freudiana na passagem para a modernidade. 2. ed. São Paulo: Boitempo, 2016. 
MORAES, Eliane R.. O corpo impossível: a decomposição da figura humana, de Lautréamont a Bataille. São Paulo: Iluminuras, 2012.

NERI, Regina. A psicanálise e o feminino: um horizonte da modernidade. Rio de Janeiro: Civilização Brasileira, 2005.

PERROT, Michele (Org.). História da vida privada, v. 4: da Revolução Francesa à Primeira Guerra. São Paulo: Companhia das Letras, 2009.

ROUDINESCO, Elisabeth; PLON, Michel. Dicionário de psicanálise. Rio de Janeiro: Zahar, 1998.

RUBIN, Gayle. O tráfico de mulheres: notas sobre a "economia política" do sexo. In: RUBIN, Gayle. Políticas do sexo. São Paulo: Ubu, 2017. p. 9-62.

SCHORSKE, Carl E. Viena fin-de-siècle: política e cultura. São Paulo: Companhia das Letras, 1988.

STRACHEY, James. Nota introductoria a algunas consecuencias psíquicas de la diferencia anatómica entre los sexos (1961). In: FREUD, Sigmund. Obras completas: Sigmund Freud. 2 ed. Buenos Aires: Amorrortu, 1976. v. XIX. 


\title{
FEMININITY AND MODERNITY IN FREUD: \\ A Critical Reading
}

\begin{abstract}
The article looks to examine the relation between modernity and femininity, according to Freud. The objective resides in the attempt to delimitate psychoanalysis as a theory and a clinical practice that emerges precisely because of the social structures of modernity, having as stepping stone the sexuality and femininity. It uses, for that, W. Benjamin in the field of Critical Theory, and Flaubert, Klimt and Baudelaire in the field of aesthetic production. With an interpretative-hermeneutical nature, it looks to establish a critical reading between Freud's texts and its time in order to comprehend how his theory is not only a product of his time, but also ahead of it, producing new ways to understand the modern subjectivity.
\end{abstract}

KEYWORDS: Psychoanalysis. Femininity. Modernity. Gender. 


\section{FEMINITE ET MODERNITE ChEZ FREUD: UNE LECTURE CRITIQUE}

\section{RÉSUMÉ}

L'article cherche à discuter la relation entre la modernité et la féminité, de Freud. L'objectif réside dans la tentative de définir la psychanalyse comme une théorie et une pratique clinique découlant des structures sociales de la modernité, avec la sexualité et la féminité comme pierre angulaire. À cette fin, W. Benjamin est employé dans le domaine de la théorie critique, et Flaubert, Klimt et Baudelaire, dans le domaine de la production esthétique. Interprétative-herméneutique, elle cherche à établir une lecture critique entre les textes de Freud et son temps, afin d'essayer de comprendre comment sa théorie est le produit de son temps, alors qu'elle est aussi en avance sur lui et produit de nouvelles formes de compréhension sur la subjectivité moderne.

MotS-CLÉs: Psychanalyse. Feminité. Modernité. Genre. 
RECEBIDO EM 27/05/2020

APROVADO EM 20/08/2020

() 2020 Psicanálise \& Barroco em revista

http://www.seer.unirio.br/index.php/psicanalise-barroco/index

revista@psicanaliseebarroco.pro.br

Programa de Pós-Graduação em Memória Social — UNIRIO

Memória, Subjetividade e Criação

www.memoriasocial.pro.br/proposta-area.php 